\title{
A Química presente nos avanços históricos, científicos e tecnológicos dos esportes
}

\author{
The chemistry in historical, scientific and technological advances of sports
}

\author{
Thaís Rios da Rocha e Mara Elisa Fortes Braibante \\ Universidade Federal de Santa Maria, RS Brasil \\ thaisufsm@gmail.com; maraefb@gmail.com
}

\begin{abstract}
Resumo
Trabalhar com a temática "esporte" no âmbito escolar possibilita a discussão e reflexão sobre questões sociais da atualidade e de conhecimento público e estabelecer suas relações com os conteúdos científicos de Química. Neste trabalho, apresentamos um histórico do esporte, dando ênfase às Olimpíadas Modernas, a conceituação de doping e as substâncias proibidas nos esportes, bem como as questões relacionadas à ética esportiva e ao fair play. Ao final do artigo são apresentadas as relações entre a temática "esporte" e o ensino de química, como possibilidade de se realizar um trabalho temático no ensino médio.
\end{abstract}

Palavras-chave: Esporte. Doping. Ensino de Química.

\begin{abstract}
Working with the theme "sport" in schools enables the discussion and reflection on social issues of our time and public knowledge and establish its relations with the chemistry scientific content. In this paper, we present a history of the sport, emphasizing the Modern Olympics, the concept of doping and banned substances in sports, as well as issues related to sports ethics and fair play. At the end of the article shows the relationship between the theme "sport" and the chemistry teaching as a possibility of conducting a thematic work in high school.
\end{abstract}

Keywords: Sport. Doping. Chemistry Teaching. 


\section{Introdução}

A importância do esporte para a sociedade está evidenciada em muitos documentos legislativos, através da elaboração de leis, programas e ações que incentivam o desenvolvimento do esporte como contribuição para a formação cidadã. Na Constituição de 1988 a prática esportiva é considerada como "direito de cada um", defendendo um conceito de cidadania com relação ao Esporte e Lazer. No ano de 1993 foi promulgada a Lei $n^{\circ} 8.672 / 93$, conhecida como Lei Zico, que propõe princípios e diretrizes para a organização e funcionamento das entidades esportivas. A Lei Agnelo/Piva de no $10.264 / 01$ estabelece que $2 \%$ da arrecadação bruta das loterias federais do país sejam repassadas ao Comitê Olímpico Brasileiro (COB) e ao Comitê Paraolímpico Brasileiro (CPB). Destacamos também o incentivo dado aos novos atletas, a partir da lei no ${ }^{-10.891 / 04, ~ c o n h e c i d a ~}$ como Bolsa-atleta, a qual possibilita melhores condições materiais de trabalho aos mesmos (BRASIL, 2005). Mais recentemente, em abril de 2013 foi estipulado um decreto de $n^{\circ} 7.984$, que institui uma série de normas gerais sobre o desporto brasileiro.

Dentro deste contexto, ressaltamos alguns aspectos importantes dos esportes nos âmbitos social, econômico e educacional. Com relação ao âmbito social, os esportes apresentam função pedagógica no processo de formação do indivíduo, ressaltando a disciplina, o respeito à hierarquia e as "regras do jogo", a solidariedade e o espírito de equipe. No âmbito econômico, que envolve muitos recursos financeiros, movimenta a indústria de produção de equipamentos esportivos, além de ser uma atividade de grande geração de empregos que envolvem técnicos, educadores físicos, nutricionistas, médicos, dirigentes, entre outros (SANTOS et al., 2004). Já no âmbito educacional, que é o foco deste trabalho, a temática "esporte" possibilita o estudo dos aspectos históricos referente aos grandes eventos esportivos de destaque mundial, bem como os aspectos químicos associados ao conceito de doping e o estudo das classes de substâncias proibidas nos esportes. Os conhecimentos científicos de Química Orgânica podem ser enfatizados através da análise das estruturas químicas das substâncias proibidas nos esportes, assim como pode ser realizada a identificação das funções orgânicas presentes nas mesmas.

Atrelado ao estudo da Química deve ser realizada uma ênfase quanto ao papel da ciência para a constante realização de pesquisas sobre as substâncias proibidas nos esportes, pois a cada ano muitos atletas vem utilizando novos medicamentos a fim de obter melhores rendimentos no esporte. Assim como a Química Orgânica, os demais conteúdos científicos de Química podem ser contextualizados com a temática "esporte", como as ligações químicas, polaridade das moléculas, cálculos químicos, termoquímica, cinética química, entre outros.

Associada a utilização de substâncias dopantes, podem ser estudados os efeitos desejados e colaterais ocasionados pela ingestão destas substâncias, assim como trabalhados os conceitos de ética esportiva e fayr-play, necessários para que se tenha uma boa convivência no âmbito esportivo. Desta forma, a temática "esporte" possibilita uma abordagem de conteúdos científicos de Química associados aos avanços da tecnologia presentes em nossa sociedade, tópicos estes que serão abordados ao longo deste artigo.

\section{Histórico dos esportes}

Para entender o reconhecimento que o esporte possui mundialmente nos dias atuais, é necessário ter uma visão geral sobre a sua história. Segundo Codeço (2007) "no mundo antigo grego, em especial ateniense, a prática atlética se inseria num extenso e complexo sistema de educação (paideía) que, na maioria absoluta das "cidades-estado" conhecidas como póleis, visava à preparação militar". Para a mesma autora, esta preparação dos guerreiros tinha por objetivo desenvolver a capacidade de combate frente a diferentes condições climáticas e geográficas. As habilidades desenvolvidas nos exércitos eram a luta corpo-a-corpo, manejo do arco e flecha, escalada, corrida e saltos. Além da preparação militar, a prática esportiva estava vinculada ao sistema educacional da região, tendo direito ao ensino apenas os homens filhos de pais atenienses, reconhecidos pela pátria e que na maior idade, tivesse livre participação na política pública (CODEÇO, 2007). Destacamos os diversos momentos festivos durante os jogos gregos, sendo realizadas procissões, competições teatrais e declamações poéticas para a comunidade. Os jogos realizados na cidade de Olímpia eram constituídos por um ritual religioso, em que os atletas vitoriosos eram associados aos deuses ou eram divinizados, sendo honrados por toda a sociedade grega (MORAES, 2007).

Pode-se dizer que foram os gregos que trouxeram a primeira concepção de esporte, instituindo uma série de regras para as modalidades esportivas, tais como a competição entre atletas com preparação física semelhante, $\mathrm{e}$ a existência da figura do treinador dando subsídios para a melhor atuação dos atletas nos Jogos Gregos. No ano de 1997, Capinussú destaca nas falas de Tubino (1991, p.33) que "a conclusão que se pode tirar do período histórico em que se desenvolveu os chamados Jogos Gregos é que, pela primeira vez na história, ocorreram fatos esportivos, e não apenas práticas esportivas".

Podemos encontrar diversas conceituações para a palavra esporte, Manoel Tubino em seu livro "O que é esporte" publicado no ano de 1993 esclarece que o termo surgiu quando os marinheiros utilizavam a expressão "fazer esporte", "desportar-se" ou "sair do porto" para explicar seus passatempos que envolviam habilidades físicas. Barbanti (2006) define esporte da seguinte maneira: "Esporte é uma atividade competitiva institucionalizada que envolve esforço físico vigoroso ou 


\section{Quadro 1 - Histórico das Olimpíadas Modernas}

\begin{tabular}{|c|c|}
\hline $\begin{array}{c}\text { Ano } \\
\text { País-sede }\end{array}$ & $\begin{array}{l}\text { Fatos marcantes } \\
\text { Momento histórico }\end{array}$ \\
\hline $\begin{array}{c}1896 \\
\text { Atenas - Grécia }\end{array}$ & $\begin{array}{l}\text { Barão de Coubertin, o idealizador do evento, criou o Comitê Olímpico Internacional (COI) com o intuito de organizar os } \\
\text { Jogos Olímpicos que seriam realizados a cada quatro anos em diferentes países (COLLI, 2004). } \\
\text { A edição especial da Revista Veja, A Olimpíada de Atenas, publicada no mês de abril de 1986, retrata este momento histórico da } \\
\text { seguinte forma: “Com as portas abertas para o mundo, a Grécia, superando as desconfianças e os problemas iniciais, realizou } \\
\text { um evento acolhedor e brilhante, celebrado por atletas e visitantes a partir dos ideais do Olimpismo". }\end{array}$ \\
\hline $\begin{array}{l}1900 \\
\text { Paris - França }\end{array}$ & $\begin{array}{l}\text { Primeira edição com a participação das mulheres, totalizando } 22 \text { atletas; e a oficialização dos esportes coletivos nas } \\
\text { Olimpíadas (COLLI, 2004; GOELLENER, 2005). O evento não obteve grandes proporções, pois na mesma época em Paris } \\
\text { ocorria uma grande Feira Mundial, tendo como principal símbolo a Torre Eiffel (RUBO, 2010). }\end{array}$ \\
\hline $\begin{array}{l}1904 \\
\text { Saint Louis, } \\
\text { EUA }\end{array}$ & $\begin{array}{l}\text { Estreia do continente africano, representado por atletas sul-africanos, e a premiação (pela primeira vez) aos três primeiros } \\
\text { colocados com medalhas de ouro, prata e bronze, respectivamente (LIMA et al., 2009). A disputa entre Rússia e Japão pelos } \\
\text { territórios da Coréia e Manchúria, iniciada no mesmo ano fez com que muitos atletas ficassem fora da competição. }\end{array}$ \\
\hline $\begin{array}{l}1912 \\
\text { Estocolmo } \\
\text { Suécia }\end{array}$ & $\begin{array}{l}\text { Pela primeira vez o evento contou com a participação dos cinco continentes: América, Ásia, África, Europa e Oceania. } \\
\text { As inovações ocorridas neste ano foram: a utilização de cronômetros eletrônicos; e o surgimento de duas modalidades } \\
\text { esportivas, natação feminina e pentatlo moderno, sendo a última constituída por cinco modalidades diferentes: natação, } \\
\text { esgrima, hipismo, tiro e corrida (RUBIO, 2010). }\end{array}$ \\
\hline $\begin{array}{c}1916 \\
\text { Jogos suspensos }\end{array}$ & $\begin{array}{l}\text { Suspenso devido aos acontecimentos políticos da época que tomaram grandes proporções desencadeando assim, a Primeira } \\
\text { Guerra Mundial, um conflito territorial entre as principais potências do mundo. }\end{array}$ \\
\hline $\begin{array}{l}1920 \\
\text { Antuérpia } \\
\text { Bélgica }\end{array}$ & $\begin{array}{l}\text { Primeira participação dos atletas brasileiros nas Olimpíadas Modernas, trazendo para o Brasil três medalhas, uma de ouro, } \\
\text { uma de prata e outra de bronze. Dois anos após o término da Primeira Guerra Mundial, uma das exigências da Bélgica foi } \\
\text { a exclusão dos países derrotados na Grande Guerra, estando entre eles a Alemanha, que durante este fato histórico invadiu } \\
\text { os territórios dos belgas. A permissão para que esses países voltassem a competir foi concedida somente nas Olimpíadas } \\
\text { realizadas no ano de } 1928 \text { (COLLI, 2004). }\end{array}$ \\
\hline $\begin{array}{l}1932 \\
\text { Los Angeles } \\
\text { EUA }\end{array}$ & $\begin{array}{l}\text { Mesmo após a Crise de 1929, os Estados Unidos conseguiram superar a crise econômica. Apesar de algumas dificuldades, } \\
\text { o evento contou com uma infraestrutura organizada, oferecendo hospedagem a seus participantes em uma Vila Olímpica } \\
\text { construída especialmente para os Jogos Olímpicos (MENEZES e SANFELICE, 2005). }\end{array}$ \\
\hline $\begin{array}{c}1936 \\
\text { Berlim } \\
\text { Alemanha }\end{array}$ & $\begin{array}{l}\text { Esta foi a primeira edição das Olimpíadas que pode ser acompanhada por todos através da televisão. Escolhido o país-sede } \\
\text { na edição anterior, o Comitê Olímpico Internacional não imaginava que a doutrina nazista estaria em ascensão e que a } \\
\text { realizãão das Olimpíadas serviria como um momento para promover os ideais do nazismo, tendo como líder Adolf Hitler } \\
\text { (SIGOĹI e DE ROSE JR, 2004). Durante a realização dos Jogos Olímpicos no ano de } 1936 \text { em Berlim, os nazistas objetivaram } \\
\text { mostrar ao mundo a existência de uma doutrina igualitária, que não condizia com a realidade. }\end{array}$ \\
\hline 1940 e 1944 & Edições canceladas devido a ocorrência da Segunda Guerra Mundial. \\
\hline $\begin{array}{l}1964 \\
\text { Japão - Tóquio }\end{array}$ & $\begin{array}{l}\text { Passados } 19 \text { anos do término da Segunda Guerra Mundial, a realização dos Jogos Olímpicos no Japão teve o intuito de } \\
\text { levar esperança ao país que ainda sofria as conseqüências da guerra. Na cerimônia de abertura das Olimpíadas de } 1964, \text { o } \\
\text { último a carregar a tocha olímpica foi o jovem nascido em Hiroshima no dia da explosão da bomba nuclear, como forma de } \\
\text { demonstração do renascimento japonês (COLLI, 2004). }\end{array}$ \\
\hline $\begin{array}{l}1980 \\
\text { Moscou -Rússia } \\
1984 \\
\text { Los Angeles } \\
\text { EUA }\end{array}$ & $\begin{array}{l}\text { Os Jogos Olímpicos realizados nestes anos ficaram conhecidos pelos boicotes políticos. No ano de 1980, decorrente da } \\
\text { invasão dos soviéticos ao território do Afeganistão, os Estados Unidos não participaram desta edição dos jogos. Devido a } \\
\text { este acontecimento os soviéticos no ano de } 1984 \text { revidaram o boicote realizado na Olimpíada anterior. O fim dos boicotes } \\
\text { ocorreu somente nos Jogos Olímpicos de } 1988 \text { (COLLI, 2004; MENEZES e SANFELICE, 2005). }\end{array}$ \\
\hline $\begin{array}{l}1988 \\
\text { Seul } \\
\text { Coréia do Sul }\end{array}$ & $\begin{array}{l}\text { Edição marcada pelo caso de doping do mexicano Ben Johnson que perdeu o título de campeão dos } 100 \text { metros livres, devido } \\
\text { a detecção de uma substância proibida que tem por objetivo aumentar a massa muscular e melhorar o desempenho do atleta } \\
\text { na corrida (COLLI, 2004; MENEZES e SANFELICE, 2005). }\end{array}$ \\
\hline $\begin{array}{l}1992 \\
\text { Espanha } \\
\text { Barcelona }\end{array}$ & $\begin{array}{l}\text { Esta edição contou novamente com a participação de atletas africanos devido ao início do processo de revogação do apartheid, } \\
\text { termo utilizado para designar a segregação racial imposta aos negros pela minoria da sociedade branca da África do Sul. } \\
\text { Foi somente no ano de } 1993 \text { que o Parlamento pôs fim ao apartheid, e em } 1994 \text { o líder Nelson Mandela foi eleito o primeiro } \\
\text { presidente negro da Âfrica do Sul, destituindo o domínio político dos brancos (COTRIM, 2009). }\end{array}$ \\
\hline $\begin{array}{c}2008 \\
\text { China } \\
\text { Pequim }\end{array}$ & $\begin{array}{l}\text { Esta edição surpreendeu devido à moderna infraestrutura oferecida aos seus participantes. Podemos destacar o crescente } \\
\text { aumento dos recordes mundiais e olímpicos ocorridos nesta edição. Com relação aos atletas brasileiros, o nadador Cesar } \\
\text { Cielo obteve um grande destaque mundial, conquistando ao final do evento esportivo uma medalha de ouro e de bronze } \\
\text { (UVINHA, 2009). }\end{array}$ \\
\hline $\begin{array}{l}\mathbf{2 0 1 2} \\
\text { Inglaterra } \\
\text { Londres }\end{array}$ & $\begin{array}{l}\text { Alguns destaques desta edição foram: a construção do Estádio Olímpico de Londres, com capacidade para oitenta mil } \\
\text { participantes; a exemplar participação do velocista jamaicano Usain Bolt que conquistou três medalhas de ouro; e o nadador } \\
\text { norte-americano Michael Phelps, recordista mundial de medalhas olímpicas (SILVA et al., 2013; OLIVEIRA et al., 2012). }\end{array}$ \\
\hline $\begin{array}{l}\mathbf{2 0 1 6} \\
\text { Rio de Janeiro } \\
\text { Brasil }\end{array}$ & $\begin{array}{l}\text { No dia } 2 \text { de outubro de 2009, o Comitê Olímpico Internacional decidiu contemplar pela primeira vez a América do Sul com } \\
\text { uma Olimpíada. Todos os preparativos necessários para a realização dos Jogos Olímpicos em nosso país, na cidade do Rio } \\
\text { de Janeiro, estão sendo providenciados, com a intenção de proporcionar a todos uma ótima acessibilidade a este grande } \\
\text { evento esportivo. } \\
\text { O orçamento inicial estabeleceu que 79,7\% dos gastos serão com obras de infraestrutura urbana (transporte, saneamento, } \\
\text { energia, segurança, hospedagem, núcleo olímpico), e 20,3\% destinados às instalações esportivas e às funções operacionais } \\
\text { do megaevento (PRONI, 2009; ATHAYDE et al., 2013; MASCARENHAS, 2013). }\end{array}$ \\
\hline
\end{tabular}




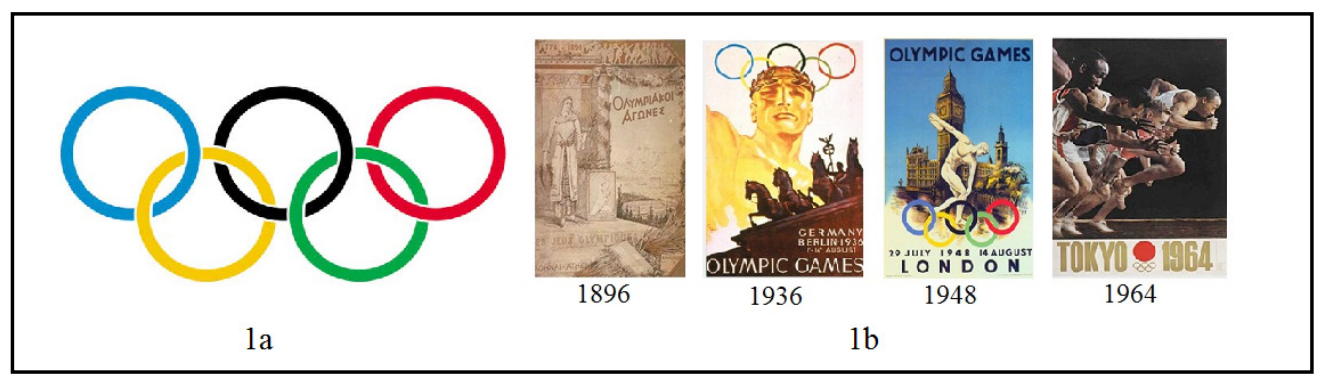

Figura 1 - 1a) Símbolo da bandeira olímpica 1b) Cartazes de divulgação das Olimpíadas Modernas Fonte: www.olympic.org

o uso de habilidades motoras relativamente complexas, por indivíduos, cuja participação é motivada por uma combinação de fatores intrínsecos e extrínsecos (BARBANTI, 2006, p. 57)".

Buscando uma aproximação com os ideais dos jogos ocorridos em Olímpia, no ano de 1896 o francês Pierre de Freddy, mais conhecido como Barão de Coubertin, revitalizou os Jogos Olímpicos na Era Moderna tendo como objetivo celebrar a união entre distintos (e rivais) Estados em torno da competição, preconizando o seguinte slogan: "O importante não é ganhar e, sim, competir" (CODEÇO, 2007). O pensamento do Barão de Coubertin deu origem ao Olimpismo, uma filosofia que destaca o papel do esporte no âmbito internacional. Podemos destacar alguns princípios fundamentais do Olimpismo, descritos na Carta Olímpica do ano de 2014:

1- Olimpismo é a filosofia de vida, exaltando e combinando balanceadamente todas as qualidades do corpo, espírito e mente. Misturando esporte com cultura e educação, Olimpismo busca criar um modo de vida baseado no prazer do empenho, o valor educacional do bom exemplo e respeito pelos princípios éticos fundamentais universais.

2- A meta do Olimpismo é colocar o esporte a serviço do desenvolvimento harmonioso do homem, com vista a promover uma sociedade pacífica preocupada com a preservação da dignidade humana (OLYMPIC CHARTER, 2014, p.11, tradução nossa).

Além da proposta de desenvolvimento das Olimpíadas Modernas, Pierre de Freddy criou o símbolo presente na bandeira olímpica que caracteriza este evento esportivo, como podemos observar na Figura 1 (a). A bandeira olímpica apresenta um fundo branco com cinco anéis entrelaçados no centro da mesma, representando os continentes do mundo. Este entrelaçamento entre os anéis caracteriza os princípios do Olimpismo como o espírito olímpico, a ética esportiva e a união através do esporte. As cores utilizadas, incluindo o fundo branco, constituem as bandeiras dos países existentes até o momento da realização dos primeiros Jogos Olímpicos da Era Moderna (LENNARTZ, 2002).

Destacamos também alguns símbolos que caracterizam as Olimpíadas Modernas, como a existência da tocha olímpica, surgindo primeiramente nos Jogos Olímpicos realizados no ano de 1936; o hino olímpico apresentado ao público no ano de 1960; o lema citius-altius-fortius que significa mais rápido, mais alto e mais forte, desenvolvido com a intenção de encorajar os atletas para a competição;e os cartazes de divulgação que apresentam imagens características do país-sede do evento, como exemplificado na Figura 1 (b).

O esporte sofreu e sofre transformações constantes em sua história de acordo com mudanças no meio social, colaborando para a formação deste evento esportivo apresentado na sociedade contemporânea (MARQUES et al., 2009). Dentro desta perspectiva histórica, iremos ressaltar os acontecimentos importantes ocorridos em algumas edições das Olimpíadas Modernas, destacando os fatos marcantes e o período histórico de realização, conforme apresentados no Quadro 1.

\section{Doping no esporte}

Estamos habituados com o termo "doping" em nossas vidas, devido à realização de inúmeros eventos esportivos nacionais e internacionais que ocorrem com grande frequência. Constantemente as informações a respeito dos casos envolvendo o doping chegam aos "amantes" do esporte através dos meios de comunicação, como noticiários transmitidos pela televisão, jornais, revistas, rádios e sites eletrônicos. A conceituação do termo doping está descrita no Código Mundial Anti-Doping e apresentada pela Agência Mundial Anti-Doping, conhecida como WADA (World Anti-Doping Agency).

O Código que entrou em vigor no ano de 2015 foi elaborado e discutido junto aos membros do conselho da WADA. Os seus escritos trazem a seguinte definição de doping: A dopagem é definida como a ocorrência de violações de regras anti-doping estabelecidas no artigo 2.1 do referido Código, que trata da detecção de substâncias proibidas descritas pela WADA, nas amostras coletadas dos atletas (WADA,2015, p.18, tradução nossa). Pereira et al. (2010) conceitua o doping da seguinte forma:

A procura de meios ou substâncias químicas capazes de alterar artificialmente o desempenho, numa atividade física ou intelectual, faz parte da cultura do Homem. Essa 
tentativa de obter um rendimento por meios não naturais, que deveria ser alcançado através de um condicionamento físico e mental eficiente, realizado em boas condições de saúde, caracteriza a dopagem (PEREIRA et al., 2010, p. 13).

Com o início da profissionalização do esporte os atletas passaram a se preparar para as competições visando à questão econômica, devido às inúmeras premiações em medalhas e em dinheiro entregues aos primeiros colocados. Sendo assim, o atleta fica a mercê da sociedade, através do envolvimento da mídia com relação às questões pessoais e profissionais, que fazem com que o mesmo almeje o status de primeiro lugar nos eventos esportivos, esquecendo-se dos ideais do Olimpismo. Deste modo, recorrem à utilização de métodos indevidos que ultrapassam os limites da moral e ética necessários para a segurança de todos os atletas envolvidos no meio esportivo. Dentro desta perspectiva, Aquino Neto (2001, p. 138) destaca que "no afã da superação, não medem esforços, empregando todos os meios disponíveis. Muitos desses artifícios representam grave risco ao atleta, seus companheiros de equipe, ou adversários". Para o mesmo autor, as causas deste comportamento indevido dos atletas devem-se ao incentivo proporcionado pelos dirigentes inescrupulosos, empresários gananciosos, treinadores e médicos do esporte irresponsáveis, "amigos" e familiares nem sempre fiéis.

Os primeiros casos de doping estão associados ao uso da substância estricnina em doses adequadas devido ao seu alto grau de toxicidade, causando aos atletas efeitos estimulantes, bem como a ingestão de cogumelos alucinógenos, que reforçam o estado psicológico do atleta antes dos jogos. Retrata-se também que durante os Jogos Olímpicos da Era Antiga, os atletas bebiam chás de ervas e ingeriam cogumelos, acreditando no aumento do seu desempenho durante a competição, que, de certa maneira, ocorria devido ao efeito das ervas no sistema nervoso (PEREIRA et al., 2010).

Como exemplo de problemas causados pelo doping, destacamos a morte do ciclista Arthur Linton no ano de 1886. Muitos pesquisadores relatam que a sua morte foi ocasionada pela administração de uma dose elevada de estricnina durante o "Tour de France", outros associam a fatalidade ao uso de Speed Ball, uma potente mistura de cocaína e heroína (AQUINO NETO, 2001).

Posteriormente a Segunda Guerra Mundial, muitos estimulantes e drogas desenvolvidos pelo exército soviético foram utilizados pelos atletas. Os esteroides anabolizantes utilizados pelos Estados Unidos durante o período pós-guerra tinham por finalidade recuperar os soldados debilitados através do aumento da força e da massa muscular (PEREIRA et al., 2010). Com a inserção dos anabolizantes sintéticos no mercado mundial no ano de 1953 , todas as modalidades tomaram conhecimento desta substância, acarretando em novos casos de doping nos esportes.

No início dos anos 60, os atletas abusavam da utilização de drogas, no entanto, esta prática ainda não era coibida. Devido a este uso exagerado, surgiu no ano de 1967 o Comitê Olímpico Internacional (COI) estabelecendo regras para o controle de dopagem, sendo devidamente utilizadas nas Olimpíadas de 1968. Com o passar dos anos novas técnicas analíticas foram desenvolvidas com a intenção de detectar as substâncias proibidas nas amostras de urina e/ou sangue dos atletas. Nos anos 2000 houve a criação de uma Agência Mundial Antidoping (WADA), que vem desenvolvendo pesquisas relacionadas aos métodos analíticos de detecção e estipula um

Quadro 2 - Classe de substâncias proibidas no esporte

\begin{tabular}{|c|c|c|c|}
\hline \multicolumn{4}{|c|}{ Classe de substâncias proibidas no esporte (WADA, 2016) } \\
\hline \multirow{6}{*}{ 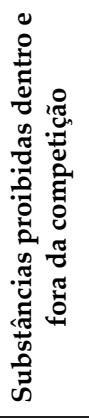 } & Simbologia & Classe & Exemplos/Observações \\
\hline & S1 & Agentes Anabólicos & Esteroides anabolizantes endógenos e exógenos. \\
\hline & S2 & $\begin{array}{c}\text { Hormônios Peptídicos } \\
\text { e Substâncias sintéticas } \\
\text { relacionadas }\end{array}$ & $\begin{array}{l}\text { Agentes estimulantes da eritropoese (EPO); Insulina; Hormônio do } \\
\text { Crescimento; Hormônio Luteinizante. }\end{array}$ \\
\hline & S3 & Beta-2 Agonistas & Todos os Beta-2 Agonistas, incluindo seus isômeros ópticos. \\
\hline & S4 & $\begin{array}{l}\text { Moduladores e Antagonistas } \\
\text { de Hormônios }\end{array}$ & Substâncias anti-estrogênicas como Clomifeno. \\
\hline & S5 & $\begin{array}{l}\text { Diuréticos e outros Agentes } \\
\text { Mascarantes }\end{array}$ & Furosemida; Clorotiazida; Dextran. \\
\hline \multirow{4}{*}{ 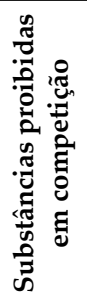 } & S6 & Estimulantes & Todos os estimulantes. Ex: Anfetamina, Cocaína, Efedrina. \\
\hline & S7 & Narcóticos & Heroína, Morfina. \\
\hline & S8 & Canabinoides & Cannabis natural e sintética. Popularmente conhecida como maconha. \\
\hline & S9 & Glicocorticoides & $\begin{array}{l}\text { Todos os métodos de administração, seja por via oral, intravenosa, } \\
\text { intramuscular ou anal, são produzidos. }\end{array}$ \\
\hline
\end{tabular}


padrão rigoroso necessário ao desenvolvimento de um controle antidoping.

Aquino Neto (2001) ressalta que na virada do século XXI as drogas sociais foram banidas, como cocaína, maconha e alucinógenos derivados de anfetaminas. Com o aumento do número de substâncias proibidas no esporte fez-se necessário a sua classificação, realizada pela Agência Mundial Antidoping e atualizada a cada ano. O Quadro 2 apresenta a classificação das substâncias proibidas na competição e fora dela, para o ano de 2016 descrita no site da Agência Mundial Antidoping (WADA).

Partindo das diferentes classes de substâncias proibidas nos esportes descritas pela Agência Mundial Antidoping, realizaremos uma breve descrição sobre cada uma delas. A primeira classe de substâncias proibidas (S1), são os agentes anabólicos. Estes esteróides anabólicos androgênicos, conhecidos como anabolizantes são um grupo de substâncias constituídas por hormônios naturais, como a testosterona, diidrotestosterona e androtenodiona, e substâncias sintéticas e semi-sintéticas que estão relacionadas com os hormônios sexuais masculinos produzidos no organismo humano (OGA et al., 2008; PEREIRA et al., 2010).

Antes mesmo da utilização dos anabolizantes como forma de aumentar o desempenho de atletas em competições, eles já eram indicados clinicamente para o tratamento de alterações hormonais, como a hipergonadotrofia, que causa o aumento das gônadas. Também promovem o crescimento da massa corpórea, principalmente para pacientes com AIDS, melhoram a circulação do sangue arterial, aumentam a síntese de proteínas contráteis da musculatura cardíaca, entre outros (OGA et al., 2008).

Weineck (2005, p. 251) ressalta o significado do efeito anabolizante como "o estímulo para a síntese protéica, que influencia o metabolismo e estimula a formação de tecidos, ou seja, estimula o crescimento dos músculos, esqueleto e órgãos", o que favorece os atletas pertencentes a modalidades esportivas que exigem uma elevada massa corporal e força muscular, como halterofilistas, fisiculturistas, lutadores, entre outros. Além disso, os anabolizantes aumentam o número de células vermelhas do sangue e da concentração de hemoglobina, devido à retenção de eletrólitos e água, que acarreta na redução do percentual de gordura. A testosterona, hormônio natural que apresenta 19 átomos de carbono, é a base de todos os anabolizantes, sendo que as substâncias sintéticas e semi-sintéticas são obtidas a partir de alterações químicas realizadas na estrutura deste esteróide, como podemos observar na Figura 2.

A utilização de substâncias anabolizantes nos esportes deve-se aos efeitos desejados das mesmas no rendimento esportivo, pois proporciona um aumento da massa muscular e agressividade. No entanto, a sua constante utilização ocasiona problemas de saúde como impotência, diminuição dos testículos, irregularidade ou ausência do ciclo menstrual, doenças cardiovasculares, complicações no fígado e na próstata, entre outros (AQUINO NETO, 2001). Para que os hormônios anabolizantes sejam detectados nas amostras de urina dos atletas, coletadas durante a competição ou fora dela, são utilizadas técnicas analíticas avançadas que permitem determinar a relação entre a concentração de testosterona (T) e epitestosterona (E). Se a relação entre essas substâncias for acima de seis para um significa que o atleta utilizou anabolizantes para alterar o seu desempenho nos esportes (OGA et al., 2008).

Pereira et al. (2010) destacam os desafios para a química com relação a detecção desses hormônios devido a concentrações baixas dos mesmos na urina, pois são rapidamente absorvidos e metabolizados pelo organismo, bem como pela semelhança na estrutura química dessas substâncias com os hormônios esteróides produzidos no organismo, havendo a necessidade de métodos analíticos que apresentam alta sensibilidade para a detecção dos mesmos. O Quadro 3 apresenta a estrutura química de dois esteróides anabolizantes, nandrolona e estanozolol utilizados como doping nos esportes, bem como a estrutura química das principais substâncias que tem seu uso proibido no esporte.

Os hormônios peptídicos (S2), são produzidos pelo nosso organismo, sendo denominados endógenos. Além da proibição desses hormônios, as substâncias que estimulam a produção dos mesmos também são banidas. $\mathrm{O}$ Quadro 4 apresenta alguns hormônios produzidos pelo organismo que pertencem a esta classe, assim como os efeitos desejados e colaterais ocasionados aos atletas.

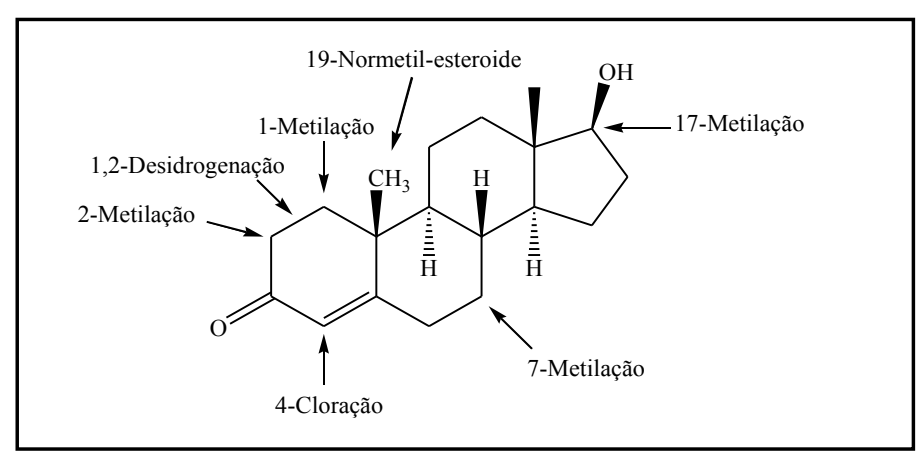

Figura 2 - Esteroide anabolizante testosterona e suas possíveis funcionalizações químicas Fonte: WEINECK (2005) 
Quadro 3 - Exemplos de substâncias proibidas no esporte

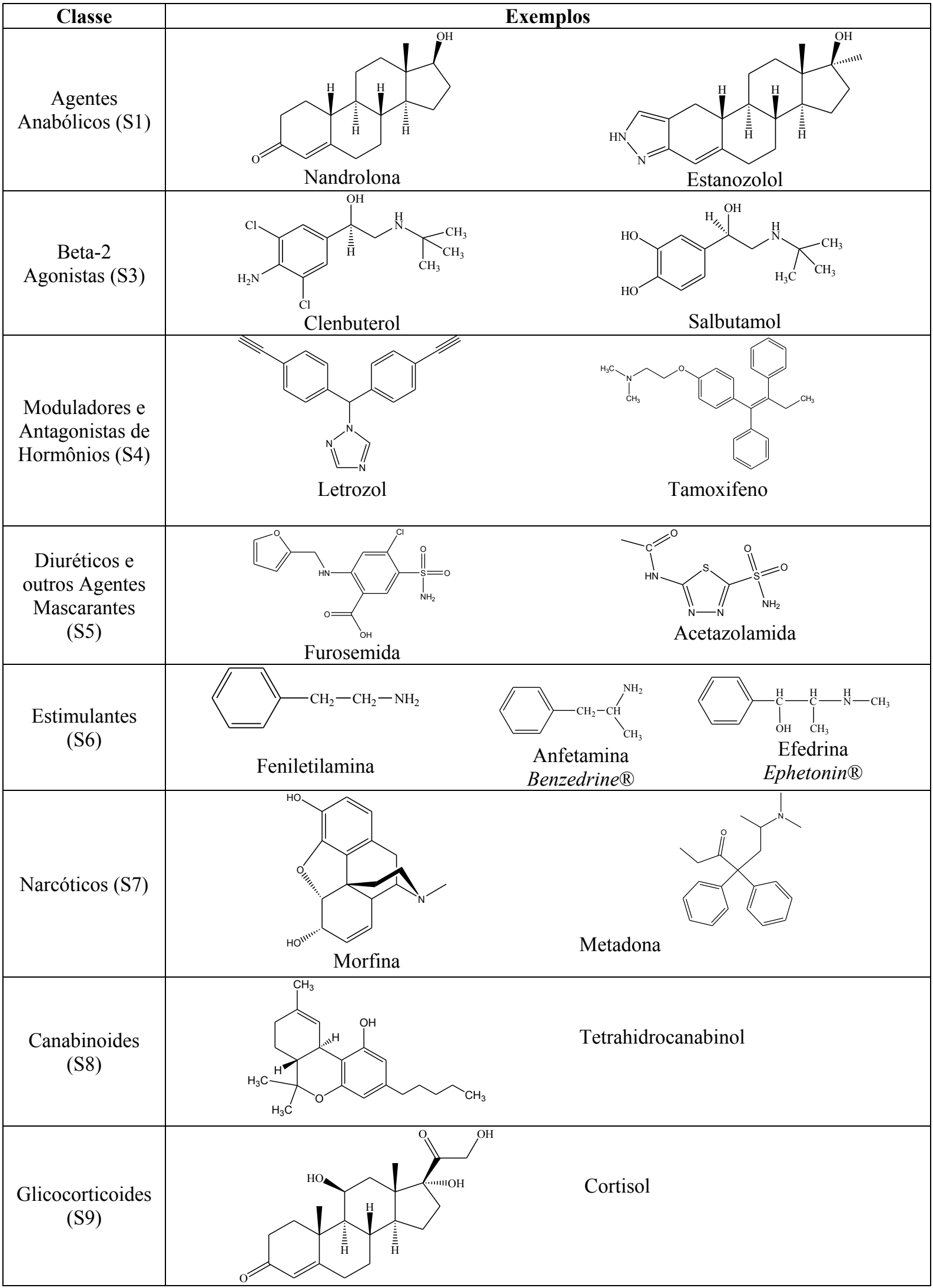

Fonte: os autores. 
Quadro 4 - Alguns hormônios pertencentes à classe S2 de substâncias proibidas nos esportes

\begin{tabular}{|c|c|c|c|}
\hline Hormônios peptídicos & Produção no organismo & Efeitos desejados & Efeitos colaterais \\
\hline $\begin{array}{l}\text { Coriongona- } \\
\text {-dotropina humana } \\
\text { HCG }\end{array}$ & $\begin{array}{l}\text { Produzido na mulher durante a } \\
\text { gravidez, estimula a produção de } \\
\text { estradiol e progesterona. }\end{array}$ & $\begin{array}{l}\text { Homens: estimula as células intersticiais } \\
\text { dos testículos, aumentando a produção } \\
\text { da testosterona. } \\
\text { Mulher: produção de estrógeno. }\end{array}$ & $\begin{array}{l}\text { Feminilização em homens, } \\
\text { cefaléia, irritabilidade, fadiga, } \\
\text { náuseas e vômitos, sintomas } \\
\text { observados em grávidas. }\end{array}$ \\
\hline $\begin{array}{l}\text { Hormônio do } \\
\text { crescimento } \\
\text { HGH }\end{array}$ & $\begin{array}{l}\text { Hormônio para o crescimento e } \\
\text { desenvolvimento do ser humano. } \\
\text { Proteína sintetizada e secretada } \\
\text { pela glândula hipófise posterior. }\end{array}$ & $\begin{array}{l}\text { Aumento da massa e da força muscular, } \\
\text { que é alcançada pela administração de } \\
\text { altas doses deste hormônio. }\end{array}$ & $\begin{array}{l}\text { Acne, sudorese, dores articulares, } \\
\text { ganho de peso, hipertensão } \\
\text { arterial, hipertrofia da tireóide. }\end{array}$ \\
\hline $\begin{array}{c}\text { Eritropoetina } \\
\text { EPO }\end{array}$ & $\begin{array}{l}\text { Hormônio produzido nos rins, } \\
\text { responsável pela produção de } \\
\text { eritrócitos (célula vermelha no } \\
\text { sangue) no corpo humano. }\end{array}$ & $\begin{array}{l}\text { Aumento do volume sanguíneo, de } \\
\text { eritrócitos e, hemoglobina, objetivando a } \\
\text { melhora da capacidade de transporte de } \\
\text { oxigênio e, dessa forma, da capacidade } \\
\text { de resistência. }\end{array}$ & $\begin{array}{l}\text { Risco de trombose ou de colapso } \\
\text { circulatório. Pode ocasionar } \\
\text { pressão arterial elevada. }\end{array}$ \\
\hline
\end{tabular}

Com relação a terceira classe de substâncias proibidas, beta-2 agonistas (S3), são indicadas no tratamento da asma, no entanto, são utilizadas com o objetivo de aumentar a resistência e diminuir a fadiga muscular. Como efeitos colaterais, ocasionam tremores musculares, diminuição da pressão sanguínea, como consequência taquicardia e palpitações, vasodilatação pulmonar, hiperglicemia, acidose lática, entre outros (AQUINO NETO, 2001). O clenbuterol e o salbutamol fazem parte dos beta-2 agonistas (Quadro 3).

Os moduladores e antagonistas de hormônios (S4) possuem uma ação antiestrogênica, tais como os inibidores de aromatase, indicados para a prevenção de cânceres de mama, conhecido comercialmente como letrozol. São utilizados como forma de aumentar os níveis de testosterona nos homens, pois esta enzima é responsável por metabolizar a testosterona em estrona. O medicamento tamoxifeno, também utilizado para tratamentos contra o câncer, é denominado como modulador seletivo de receptores estrogênicos, o qual possui a mesma ação no organismo que o medicamento letrozol. As estruturas químicas destes compostos são apresentadas no Quadro 3.

Os diuréticos são substâncias proibidas (S5) utilizadas pelos atletas com o objetivo de aumentar o fluxo urinário para que haja alterações nas concentrações de outras substâncias na urina, atuando assim, como um agente mascarante. Contribui também para a redução do peso corporal em um curto espaço de tempo, para que o atleta possa se enquadrar nas modalidades esportivas constituídas por categorias de peso. Como efeitos indesejados, os atletas apresentam sintomas como desidratação, dores de cabeça, câimbras, vertigens e problemas renais. $\mathrm{Na}$ área médica, os diuréticos são utilizados em tratamentos de hipertensão, cirrose hepática, problemas cardíacos e renais, além de atuarem para a prevenção de retenção de líquidos pelo organismo (PEREIRA et al., 2010; OGA et al., 2008). São exemplos de diuréticos a furosemida e a acetazolamida (Quadro 3).

A sexta classe de substâncias proibidas nos esportes (S6) é conhecida como estimulantes, uma das primeiras drogas que foram utilizadas no esporte, pois tem como objetivo aumentar o desempenho esportivo. Desde a Segunda Guerra Mundial os soldados já recorriam às anfetaminas para manter o estado de alerta e retardar o aparecimento de fadiga. Dentro deste contexto, os estimulantes caracterizam-se como substâncias que atuam no Sistema Nervoso Central (SNC), fazendo com que haja a liberação de neurotransmissores como dopamina, noradrenalina e serotonina nos terminais nervosos, que promovem o aumento do estado de alerta e a redução da fadiga, contribuindo assim, para aumentar a competitividade dos atletas durante os eventos esportivos (PEREIRA et al., 2010; OGA et al., 2008).

Normalmente essas substâncias são utilizadas momentos antes da competição, para manter o estado de excitação e melhorar o desempenho esportivo, ou também durante o período de treinamento, para que haja a possibilidade de se realizar treinos mais longos. No entanto, o abuso dos estimulantes pode ocasionar sérios problemas aos atletas como o aumento da pressão arterial, dor de cabeça, arritmia cardíaca, ansiedade e tremores (AQUINO NETO, 2001).

Dentre as substâncias pertencentes a esta classe, destacamos as aminas simpatomiméticas, que imitam a ação dos transmissores do sistema nervoso autônomo simpático, são exemplos: as anfetaminas, utilizadas no tratamento da narcolepsia e hiperatividade de crianças; e as efedrinas e pseudoefedrinas, auxiliam no tratamento dos sintomas da gripe (WEINECK, 2005). A feniletilami- 
na, estrutura básica dos compostos simpatomiméticos, assim como a estrutura química da anfetamina e efedrina, encontram-se no Quadro 3.

Os narcóticos, termo empregado para designar as substâncias provenientes do ópio, tais como a morfina, também conhecidos como anestésicos, fazem parte da sétima classe de substâncias proibidas nos esportes (S7). São incluídos nesta classe tanto os narcóticos quanto os analgésicos, ambos atuam no sistema nervoso central (SNC) através da supressão ou eliminação da dor. Como efeitos colaterais destas substâncias, destacamos a depressão respiratória, dependência física e mental grave, assim como problemas na musculatura e articulações (AQUINO NETO, 2001). A morfina e a metadona pertencem a esta classe de substâncias (Quadro 3).

Os canabinóides (S8) são substâncias provenientes da Cannabis, como a maconha e o haxixe, são utilizadas com o objetivo de proporcionar euforia aos atletas no momento da competição, a redução da ansiedade e facilitar a sociabilidade no momento das provas, devido ao nervosismo. Entretanto, seu uso de forma aguda pode causar a redução do desempenho do atleta em exercícios de resistência, a diminuição do estado de alerta e dos reflexos nos esportes (OGA et al., 2008). O principal princípio ativo das espécies pertencentes ao gênero Cannabis é o tetrahidrocanabinol (THC), conforme sua estrutura química apresentada no Quadro 3.

A última classe de substâncias proibidas nos esportes (S9), é constituída pelos glicocorticóides, utilizados clinicamente como anti-inflamatórios, analgésicos e no tratamento da asma. Nos esportes, a substância mais conhecida é o cortisol (Quadro3), que atua juntamente com o glucagon e as catecolaminas para o aumento da glicose no sangue, havendo uma maior liberação de ácidos graxos livres. Weineck (2005) destaca ainda que o cortisol inibe a síntese de proteínas estimulando a sua degradação para a obtenção de glicose, o que favorece atletas de resistência. A utilização indevida dos glicocorticóides pode provocar efeitos colaterais como problemas cardiovasculares, fadiga crônica e rompimentos musculares (AQUINO NETO, 2001).

Pereira et al (2010, p. 20) destaca que "a análise de controle de dopagem no esporte se tornou um campo multidisciplinar de estudo, pois associa diversos conhecimentos que vão desde a Química Analítica e a Química Orgânica até as áreas da Farmacologia, Bioquímica e Fisiologia Humana". A Agência Mundial Antidoping utiliza amostras de urina dos atletas para a detecção das substâncias proibidas listadas anteriormente.

\section{4 Ética esportiva e Fayr-play}

Quando colocamos em discussão as causas que levam os atletas a utilizar substâncias proibidas no esporte, algumas questões merecem devido destaque, tais como a ética esportiva e o fair-play, essenciais para o bom relacionamento entre os profissionais do esporte. Costa et al. (2005) ressaltam que a violação de leis e métodos proibidos no esporte, com o intuito de vencer a qualquer preço confere ao atleta um comportamento injusto com os demais participantes, considerando o mesmo eticamente condenável. $\mathrm{O}$ autor apresenta argumentos do senso comum referentes a prática indevida do doping, que são: a existência de uma legislação sobre o esporte que proíbe o uso de substâncias e métodos que contribuem para o aumento do desempenho do atleta, devendo respeitá-la; por serem substâncias não naturais, são prejudiciais à saúde; contribui para a existência de desigualdade entre atletas; e que o doping não pode ser utilizado sob pretexto legal, físico e moral, podendo submeter-se a uma infração ética havendo uma punição.

Partindo desses argumentos, fica claro que todos os métodos indevidos que contribuem para que o atleta apresente um aumento de seu desempenho nas competições, ferem a ética fundamental para a prática esportiva. Para Capinussú (2004, p. 73), “os sociólogos colocam a ética como um atributo indispensável à prática das atividades esportivas de forma limpa, honesta e bonita", considerando que a não existência de ética nessas práticas vincula-se as grotescas manifestações esportivas realizadas na Roma Antiga. Destaca ainda alguns atos éticos que ocorrem no esporte, como: a gentileza do atleta em esportes coletivos ao estender a mão para auxiliar um adversário a se levantar, em virtude da disputa de um lance acirrado; a atitude de um jogador lançando a bola fora do campo de futebol ao perceber que um adversário está caído ao chão devido a uma jogada ríspida, e; o cumprimento do vencedor ao vencido manifestado por um aperto de mão.

"Sob o prisma da ética do esporte, a questão do doping está intrinsecamente ligada à noção do 'jogo justo' e por conseguinte a um conjunto de comportamentos genericamente encapsulados no conceito de fair play (TAVARES, 2002, p. 44)", que pode ser entendido como "jogo limpo" ou apresentando uma ideia de "espírito esportivo". O fair play vai ao encontro da ética esportiva, pois prioriza o bom comportamento dos atletas nas competições esportivas através da aceitação de regras e respeito entre os adversários, princípios do Olimpismo descritos na Carta Olímpica, como mencionado anteriormente.

O "fair-play" é uma forma de ser, baseada no respeito a si mesmo e que implica em honestidade, lealdade e atitude firme e digna ante a um comportamento desleal; respeito ao adversário, vitorioso ou vencido, com a consciência de que é o companheiro indispensável; solidariedade na camaradagem esportiva, da qual fazem parte o apreço ao companheiro; e o devido respeito ao árbitro (CAPINUSSU, 2004, p. 75-76). 
Com o intuito de levar à sociedade os ideais do Olimpismo que constituem a ética esportiva e o espírito competitivo, respeitando todas as formas de manifestação esportiva, o Ministério do Esporte no ano de 2005 apresentou o Plano Nacional do Esporte, tendo como objetivos: democratizar e universalizar o acesso ao esporte e lazer; promover a construção e o fortalecimento da cidadania, assegurando o acesso às práticas esportivas e ao conhecimento científico e tecnológico a elas inerente; descentralizar a gestão das políticas públicas de esporte e lazer; fomentar a prática do esporte de caráter educativo e participativo para toda a população; incentivar o desenvolvimento de talentos esportivos em potencial e aprimorar o desempenho de atletas de rendimento (BRASIL, 2005).

Com relação à prática de esportes no âmbito educacional, podemos destacar algumas implementações pelo Ministério do Esporte, como os Jogos Escolares da Juventude, o Programa Esporte e Lazer na Cidade, e o Programa Segundo Tempo na Escola. Estes programas visam à democratização do acesso à prática e à cultura do Esporte, promovendo assim o desenvolvimento integral de crianças, adolescentes e jovens. Por fim, Bassani et al. (2003, p. 90) ressalta que o esporte apresenta um grande destaque em ambientes escolares, " [...]tanto como conteúdo central da Educação Física Escolar, quanto como prática extracurricular, os esportes são motivo de canalização de importantes recursos financeiros, materiais e simbólicos nas escolas brasileiras."

\section{A temática "esporte" e o Ensino de Química}

A abordagem temática proposta neste trabalho tem a intenção de proporcionar uma efetiva relação entre os conhecimentos científicos e tecnológicos com os temas sociais presentes no cotidiano dos alunos, despertando assim, a curiosidade dos mesmos em aprender a Química presente no tema. Nesse sentido, a temática "esporte" permite a realização de discussões de temas atuais e sociais sob uma perspectiva CTS, como podemos observar na Tabela 1.

Para o desenvolvimento das atividades relacionadas com a temática "esporte", os assuntos propostos precisam estar relacionados com situações e/ou eventos presentes na vida dos estudantes, permitindo assim a interação dos mesmos nas discussões, questionamentos e reflexões propiciadas a partir da perspectiva CTS. Utilizar situações do cotidiano dos alunos, como os fatos ocorridos durante os Jogos Olímpicos Modernos, é fundamental para que o mesmo reconheça a importância da Química na sociedade, pois durante o evento muitos assuntos são discutidos como os avanços científicos, o surgimento de novas substâncias e materiais, o metabolismo artificial e a sua influência no desempenho do atleta, os quais permitem a contextualização com os conteúdos de Química trabalhados em sala de aula, assim como promovem um diálogo entre professores e alunos. O Quadro 5 apresenta os diversos conteúdos de Química que possibilitam a contextualização com o esporte.

O estudo dos conteúdos científicos de Química mencionados no Quadro 5 pode ser realizado a partir de três

Tabela 1 - Temática "esporte” sob uma perspectiva CTS

\begin{tabular}{|c|c|}
\hline Assunto proposto & Perspectiva CTS \\
\hline $\begin{array}{l}\text { Eventos esportivos } \\
\text { de grande destaque } \\
\text { mundial como a } \\
\text { Copa do Mundo e as } \\
\text { Olimpíadas }\end{array}$ & $\begin{array}{l}\text { - Analisar a conduta ética e anti-ética dos atletas nas competições esportivas e propor alternativas } \\
\text { para que não ocorra atitudes indevidas no esporte; } \\
\text { - Trabalhar o conceito de doping e fair-play através de reflexões sobre casos ocorridos em } \\
\text { competições; } \\
\text { - Discutir os motivos que causam a violência no esporte; } \\
\text { - Debater questões políticas e econômicas envolvidas no momento da escolha do país sede desses } \\
\text { eventos mundiais. }\end{array}$ \\
\hline $\begin{array}{l}\text { Modalidades } \\
\text { esportivas }\end{array}$ & $\begin{array}{l}\text { - Conhecer as diferentes modalidades esportivas existentes e o tipo de treinamento que cada uma } \\
\text { exige, associadas ao uso de substâncias proibidas no esporte que conferem efeitos desejados e } \\
\text { colaterais ao atleta. }\end{array}$ \\
\hline Qualidade de vida & $\begin{array}{l}\text { - Estudar as reações que ocorrem em nosso organismo durante a prática de exercícios físicos; } \\
\text { - Perceber a influência de uma alimentação balanceada para a obtenção de uma vida saudável. }\end{array}$ \\
\hline Avanços tecnológicos & $\begin{array}{l}\text { - Realizar uma abordagem histórica com relação aos avanços tecnológicos e científicos associados } \\
\text { aos materiais esportivos; } \\
\text { - Analisar o uso da nanotecnologia nos materiais e vestimentas esportivos; } \\
\text { - Promover reflexões acerca do seguinte questionamento: “a tecnologia e nanotecnologia aplicada } \\
\text { aos materiais e vestimentas esportivos influenciam no desempenho do atleta?”. Fazer relação com } \\
\text { casos verídicos em que há o uso dos materiais nanotecnológicos; } \\
\text { - Utilização de métodos analíticos avançados para a análise e detecção de substâncias. }\end{array}$ \\
\hline Papel da ciência & $\begin{array}{l}\text { - Discutir a importância da realização de pesquisas científicas para o surgimento de novos materiais } \\
\text { e substâncias. }\end{array}$ \\
\hline
\end{tabular}


Quadro 5 - Conteúdos científicos de Química e a temática "esporte"

\section{Conteúdos científicos de Química}

Elementos da tabela periódica;

Ligações químicas;

Polaridade das moléculas;

Funções inorgânicas;

Balanceamento das equações químicas.

Cálculos químicos;

Soluções químicas;

Termoquímica;

Cinética Química;

Equilíbrio Químico.

Classificação e hibridização dos carbonos;

Análise das cadeias carbônicas e sua classificação;

Nomenclatura dos compostos orgânicos;

Funções orgânicas;

Química descritiva.

diferentes enfoques, tais como: a Química dos materiais esportivos, através da abordagem do conteúdo de polímeros associado aos avanços tecnológicos e nanotecnológicos nos esportes; a Bioquímica do exercício físico, abordando a necessidade de se realizar uma alimentação balancea$\mathrm{da}$, sendo realizado o estudo dos diferentes nutrientes presentes nos alimentos, assim como a bioenergética envolvida durante a realização de exercícios físicos; e o estudo das substâncias proibidas nos esportes, tópico que foi abordado ao longo deste trabalho.

A realização de uma abordagem CTS permite que o aluno interaja com os demais colegas e com o professor, buscando (re)construir o seu pensamento químico através da relação com os assuntos da sociedade. No momento em que a opinião dos alunos é considerada, as abordagens alternativas podem ser consideradas como construtivistas, sociointeracionistas ou históricosociais, o que se diferenciam das concepções de ensino tradicional, em que o aluno é tábula-rasa e a aprendizagem ocorre através da transmissão de informações (SCHNETZLER, 2010).

Nessa perspectiva, uma das metodologias de ensino que pode ser utilizada para trabalhar os conteúdos de Química relacionados à temática "esporte" é o método do estudo de casos. Esta metodologia permite a realização de atividades que desenvolvem o pensamento crítico e a tomada de decisões sobre questões sociais, ambientais, econômicas e éticas a partir de uma situação-problema, associando os conhecimentos científicos com a prática apresentada através dos casos (SERRA e VIEIRA, 2006; SÁ e QUEIROZ, 2009; SÁ et al., 2007). A utilização de fatos reais para a construção de casos, como a dopagem de atletas durante os Jogos Olímpicos da Era Moderna, é uma possibilidade para o desenvolvimento da temática "esporte" no âmbito escolar (Autores, 2015). Serra e Vieira (2006, p. 19) argumentam que "casos são relatos de situações ocorridas no "mundo real", apresentadas a estudantes com a finalidade de ensinar, preparando-os para a prática".
O nosso grupo de pesquisa em Ensino de Química, LAEQUI/UFSM desenvolveu um trabalho utilizando a temática "esporte", através da realização de uma abordagem diferenciada para trabalhar os conteúdos de Química Orgânica, ao longo do ano letivo de 2013, com estudantes da terceira série do ensino médio. A pesquisa desenvolvida apresentou os três diferentes enfoques mencionados anteriormente: a química dos materiais esportivos; a bioquímica do exercício físico; e o estudo das substâncias proibidas nos esportes. Foi possível evidenciar a partir dos resultados desta pesquisa que a utilização da temática "esporte" favoreceu a compreensão de conhecimentos científicos de química e sua relação com outras áreas do conhecimento, através do desenvolvimento de metodologias de ensino que permitiram a participação ativa dos estudantes, promovendo um maior interesse e envolvimento dos mesmos durante a realização das atividades no âmbito escolar (Autor 1, 2014).

\section{Considerações finais}

A utilização da temática "esporte" para o desenvolvimento de atividades no âmbito escolar possibilita trabalhar questões sociais da atualidade e de conhecimento público, relacionadas aos conteúdos científicos de Química, principalmente abordando conteúdos de Química Orgânica, a partir da análise das substâncias proibidas nas competições esportivas. Ao utilizar a temática "esporte" muitos assuntos podem ser abordados como a ética e anti-ética no esporte, o doping realizado pelos atletas com o intuito de aumentar o seu desempenho nas competições, os avanços da ciência com relação aos materiais tecnológicos no esporte, as questões políticas e econômicas que permeiam os eventos mundiais esportivos, os cuidados com a alimentação para a obtenção de uma vida saudável, entre outros assuntos. Este tipo de abordagem permite ao estudante momentos de reflexões e discussões a respeito de situações reais, promovendo assim, o desenvolvimento da capacidade de tomada de decisões e resoluções de problemas, necessários para a formação cidadã dos mesmos. Além disso, é possível realizar um trabalho juntamente com as demais áreas do conhecimento, relacionados com as disciplinas de História, área das Humanas; Biologia, área das Ciências da Natureza; e Educação Física, área das Linguagens.

Sendo assim, a utilização da temática "esporte" possibilita um amplo estudo dos temas sociais relacionados aos conteúdos científicos trabalhados no ensino médio, o que vai ao encontro das ideias propostas pelas Orientações Curriculares Nacionais do Ensino Médio (BRASIL, 2006), ressaltando que a organização curricular por áreas do conhecimento tem por objetivo promover ações interdisciplinares, abordagens complementares e transdisciplinares, contribuindo para um avanço na área educacional. 


\section{Referências}

AQUINO NETO, F. R. O papel do atleta na sociedade e o controle de dopagem no esporte. Revista Brasileira de Medicina do Esporte, v. 7, n. 4, p. 138-148, Jul./Ago. 2001.

ATHAYDE, P.; MASCARENHAS, F.; MATIAS, W. B.; MIRANDA, N. N. Revista Pensar a Prática, v. 16, n. 3, jul/set. 2013.

AUTOR 1, 2014.

AUTORES, 2015.

BARBANTI, V. O que é esporte?Revista Brasileira de Atividade Física \& Saúde, v. 11, n. 1, p. 54-58, 2006.

BASSANI, J. J.; TORRI, D.; VAZ, A. F. Sobre a presença do esporte na escola: paradoxos e ambigüidades. Revista Movimento, Porto Alegre, v. 9, n.2, p. 89-112, mai/ago 2003.

BRASIL. Ministério da Educação, Secretaria de Ensino Básico. Parâmetros Curriculares Nacionais do Ensino Médio: Ciências da Natureza, Matemática e suas Tecnologias. Orientações Curriculares para o Ensino Médio. v. 2. Brasília, 2006.

BRASIL. Ministério do Esporte. Política Nacional do Esporte. Brasília, ME, 2005.

CAPINUSSÚ, J. M. Análise de condutas éticas e antiéticas na prática desportiva. Revista de Educação Física, Rio de Janeiro, n. 128, p. 73-78, 2004.

CAPINUSSÚ, J. M. Comunicação e transgressão no esporte. São Paulo: Ibrasa, 1997.

CODEÇO, V. F. S. Paidéia e educação esportiva: uma perspectiva comparada. In: MELO, V. A. de (Org). História Comparada do Esporte. Rio de Janeiro: editora Shape, 2007, p. 90-103.

COLLI, E. Universo Olímpico: uma enciclopédia das Olimpíadas. São Paulo: Editora Códex, 2004.

COSTA, F. S. da. et al. Doping no esporte - problematização ética. Revista Brasileira de Ciências do Esporte, v. 27, n. 1, p. 113-122, set. 2005.

COTRIM, G. História Global:Brasil e Geral. 8. ed.São Paulo: Editora Saraiva, 2009.

GOELLNER, S. V. Mulher e esporte no Brasil: entre incentivos e interdições elas fazem história. Revista Pensar a Prática, v. 8, n. 1, jan/jun. 2005.
LENNARTZ, K. The Story of the Rings. The Journal of Olympic History. v. 10. Dec. 2001/jan. 2002.

LIMA, M. A. de.; MARTINS, C. J.; CAPRARO, M. A. Olimpíadas Modernas: a história de uma tradição inventada. Revista Pensar a Prática, v. 12, n. 1, p. 1-11, jan. /abr. 2009.

MARQUES, R. F. R. et al. Esporte Olímpico e Paraolímpico: coincidências, divergências e especificidades numa perspectiva contemporânea. Revista Brasileira de Educação Física e Esporte, v. 23, n. 4, p. 365-377, out. / dez. 2009.

MASCARENHAS, G. Londres 2012 e Rio de Janeiro 2016: conceito e realidade na produção da Cidade Olímpica. Revista Continentes, ano 2, n. 3, 2013.

MENEZES, F. C. L.; SANFELICE, G. R. The politics and the Olympianism. The FIEP Bulletin, Foz do Iguaçu/ PR, v. 75, n. I, p. 605-608, 2005. Disponível em: <http:// migre.me/pRmFe > Acesso em: 14 mai. 2015.

MORAES, A. S. A construção dos atletas vencedores: Grécia antiga e Brasil atual em uma perspectiva comparada. In: MELO, V. A. de (Org). História Comparada do Esporte. Rio de Janeiro: editora Shape, 2007. p. 105-123.

OGA, S.; CAMARGO, M. M. de A.; BATISTUZZO, J. A. de O. Fundamentos de toxicologia.3. ed. São Paulo: Editora Atheneu, 2008.

OLYMPIC CHARTER. International Olympic Committee. Disponível em:<http://www.olympic.org/Documents/ olympic_charter_en.pdf $>$. Acesso em 06 Mai. 2015.

OLIVEIRA, A. V.; PIMENTEL, G. G. A.; MÜHLEN, J. C. V. O corpo olímpico no cubo d'água. Revista Motrivizência, n. 38, jun. 2012.

PEREIRA, H. M. G.; PADILHA, M. C.; AQUINO NETO, F. R. A Química e o Controle de Dopagem no Esporte, v. 3. São Paulo: Sociedade Brasileira de Química, 2010. (Coleção Química no Cotidiano).

PRONI, M. W. Observações sobre os impactos econômicos esperados dos jogos olímpicos 2016. Revista Motrivizência, n. 32/33, Jun./Dez. 2009.

RUBIO, K.Jogos Olímpicos da Era Moderna: uma proposta de periodização. Revista Brasileira de Educação Física e Esporte, v. 24, n. 1, p. 55-68, jan./mar. 2010.

SÁ, L. P.; FRANCISCO, C. A.; QUEIROZ, S. L. Estudos de caso em Química. Revista Química Nova, v. 30, n. 3, p. 731-739, 2007. 
SÁ, L. P.; QUEIROZ, S. L. Estudo de casos no Ensino de Química. São Paulo: Editora Átomo, 2009.

SANTOS, W. L. P. dos. et. al. Química e sociedade: Uma experiência de abordagem temática para o desenvolvimento de atitudes e valores. Revista Química Nova na Escola, n. 20, nov. 2004.

SCHNETZLER, R. P. Apontamentos sobre a História do Ensino de Química no Brasil. In: SANTOS, W. L. P. dos; MALDANER, O. A. (Org). Ensino de Química em foco. Ijuí: Unijuí, 2010. p. 51-75.

SERRA, F.; VIEIRA, P. S. Estudos de Casos: como redigir, como aplicar. Rio de Janeiro: LTC, 2006.

SIGOLI, M. A.; DE ROSE JR, D. A história do uso político do esporte. Revista Brasileira de Ciência e Movimento,v. 12, n. 2, p. 111-120, 2004.

SILVA, P. R. P. da.; RIBEIRO, C. H. V.; COSTA, L. P. da. A cobertura esportiva dos Jogos Olímpicos de Londres 2012: a tematização do "doping" no portal de notícias G1. Revista Brasileira de Educação Física e Esporte, v. 27, n. 3, jul/set. 2013.

TAVARES, O. Doping: argumentos em discussão. Revista Movimento, Porto Alegre, v. 8, n.1, p. 41-55, jan/abr. 2002.

UVINHA, R. R. Os megaeventos esportivos e seus impactos: o caso das Olimpíadas da China. Revista Motrivizênncia, ano XXI, n. 32/33, p. 104-125, Jun./Dez. 2009.

WADA. The World Anti-doping code: the prohibited 2015 list. Disponível em: <http://list.wada-ama.org/>. Acesso em: 27Jan. 2016.

WEINECK, J. Biologia do esporte. Tradução: Luciano Prado. 7. ed. São Paulo: Editora Manole, 2005. 